\title{
Neuroactive steroids after estrogen exposure in depressed postmenopausal women treated with sertraline and asymptomatic postmenopausal women
}

\author{
Melinda L. Morgan • Andrea J. Rapkin • \\ Giovanni Biggio • Mariangela Serra • \\ Maria Giuseppina Pisu • Natalie Rasgon
}

Received: 26 March 2009 / Accepted: 17 August 2009 / Published online: 3 September 2009

(C) The Author(s) 2009. This article is published with open access at Springerlink.com

\begin{abstract}
Neuroactive steroids (NAS) allopregnanolone (ALLO), Allotetrahydrodeoxycorticosterone (THDOC) and dehydroepiandrosterone (DHEA) are important in the regulation of mood and behavior. Knowledge about these steroids in postmenopausal depression and the effect of estrogen on NAS is lacking. We elected to determine if there were differences in NAS between postmenopausal depressed women and age matched controls. We also investigated the effect of estradiol on NAS in post menopausal depressed women receiving a selective serotonin reuptake inhibitor (SSRI), and in non-depressed postmenopausal controls. As part of a previously published double blind study on estrogen acceleration of antidepressant action, post menopausal women with major depression receiving sertraline and healthy non depressed controls were randomized to transdermal estrogen patch $0.1 \mathrm{mg}$ or placebo. NAS were measured at baseline and after 10 weeks
\end{abstract}

M. L. Morgan · A. J. Rapkin $(\triangle)$

Department of Obstetrics and Gynecology,

David Geffen School of Medicine at UCLA,

10833 Le Conte Avenue,

Los Angeles, CA 90095-1740, USA

e-mail: arapkin@mednet.ucla.edu

G. Biggio $\cdot$ M. Serra

Department of Experimental Biology,

Center of Excellence for Neurobiology of Dependence,

University of Cagliari,

Cagliari, Italy

M. G. Pisu

C.N.R. Institute of Neuroscience,

Cagliari, Italy

N. Rasgon

Department of Psychiatry and Behavioral Sciences,

Stanford University,

Palo Alto, CA, USA of treatment. Depressed subjects were treated with sertraline $50 \mathrm{mg} /$ day to $100 \mathrm{mg} /$ day for 9 weeks. At the baseline and after treatment ALLO and DHEA were significantly lower in depressed women compared to controls. Although all depressed subjects experienced a positive clinical response, estrogen administration was not associated with changes in NAS in either the depressed or the asymptomatic postmenopausal women. The lower ALLO and DHEA in postmenopausal depressed women suggests that symptoms of depression may be influenced by the synthesis or fluctuation of these NAS. Estradiol exposure did not alter ALLO, DHEA, or THDOC, implying these NAS are unlikely to play a role in any mood changes in post menopausal women given estrogen therapy.

Keywords Neuroactive steroids · Allopregnanolone · Dehydroepiandrosterone $\cdot$ Postmenopausal depression . Selective serotonin reuptake inhibitor

\section{Introduction}

Steroids synthesized in the central nervous system can influence neurophysiologic processes, mood, and behavior. The term "neurosteroid" refers to endogenous steroids synthesized from cholesterol in the central and peripheral nervous system, independent of steroidogenic activity of the endocrine glands (Baulieu 1991). The term "neuroactive steroid" (NAS) subsequently was used to refer to endogenous or exogenous steroids that have a direct nongenomic effect on neuron excitability (Paul and Purdy 1992; Lambert et al. 1995; Rupprecht 2003; StoffelWagner 2001; Pisu and Serra 2004). NASs bind to a distinct site on the $\mathrm{GABA}_{\mathrm{A}}$ receptor and influence the frequency and duration of the chloride channel openings, 
thus modulating GABAergic transmission and GABA mediated behaviors (Paul and Purdy 1992; Lambert et al. 1995; Majewska 1992; Concas et al. 1999). Potent neuroactive steroid modulators of the $\mathrm{GABA}_{\mathrm{A}}$ receptor function include allopregnanolone (ALLO), allotetrahydrodeoxycorticosterone (THDOC), and dehydroepiandrosterone (DHEA) (Rupprecht 2003; Majewska 1992). THDOC and ALLO act as positive allosteric agonists of the $\mathrm{GABA}_{\mathrm{A}}$ receptor while DHEA in the sulfated form can display antagonistic properties at the $\mathrm{GABA}_{\mathrm{A}}$ receptor (Majewska 1992).

Several authors have suggested that the disequilibrium of NASs may be a factor in the pathogenesis of major depression or a risk factor for the development of affective symptoms (Rupprecht 2003; Pisu and Serra 2004; Bernardi et al. 2004; Strous et al. 2006). In animal models of depression, lower levels of allopregnanolone have been found in the frontal cortex and amygdala (Uzunova et al. 2003). Exogenous administration of ALLO and DHEA in preclinical and clinical models demonstrated antidepressant effects (Uzunova et al. 2003; Khisti and Chopde 2000; Khisti et al. 2000; Matsumoto et al. 1999; Pinna et al. 2003; Serra et al. 2002; Wolkowitz et al. 1999). NAS have also been implicated in the positive effect of selective serotonin reuptake inhibitors (SSRIs). SSRIs were shown to catalyze the rate limiting step in the synthesis of ALLO (Mellon and Griffen 2002). In the olfactory bulbectomized rodent model of depression, treatment with different antidepressant medications that affect serotonin reversed the bulbectomyinduced decline of ALLO (Uzunova et al. 2004; Uzunova et al. 2006).

Menopause represents a time of vulnerability for onset of depressive disorders (Rubinow et al. 1998; Joffe and Cohen 1998; Cohen et al. 2005); between 22 and 33\% of menopausal women report mood deterioration and depression (Zweifel and Obrien 1997). Significant changes in hormonal concentrations occur at the time of menopause. Estrogen concentrations decline precipitously and the ensuing hypoestrogenic state has been linked with substantial alterations in physical and psychological functioning. Estrogen deficiency has been proposed to increase the susceptibility for depression (Birkhauser 2002). In a large meta-analysis, estrogen therapy appeared to be effective in reducing symptoms of depression in menopausal women (Zweifel and Obrien 1997). Exogenous estrogen has been a useful monotherapy in treating depression during the menopausal transition (Schmidt et al. 2000; Soares et al. 2001; Rasgon et al. 2002; Cohen et al. 2003), as well as an augmentation strategy to antidepressant medication (Westlund and Parry 2003; Liu et al. 2004; Morgan et al. 2005). Studies in postmenopausal depression however, have not been as consistent (Cohen et al. 2005; Morrison et al. 2004; Rasgon et al. 2007).
Estrogen has been proposed to alleviate depression via influencing serotonin and norepinepherine (Bethea et al. 2002). However, it has also been proposed that the deterioration in mood in menopausal women may be related to changes in levels of neuroactive steroids (Genazzani et al. 2005). Similar to estrogen, neuroactive steroids also decline post menopausally (Bernardi et al. 2003; Barbaccia et al. 2000; Genazzani et al. 1998), and could conceivably contribute to menopausal depression. Exposures to a variety of menopausal hormone treatments have been shown to increase ALLO and decrease DHEA in non-depressed postmenopausal women (Bernardi et al. 2003; Pluchino et al. 2005). NAS have not been evaluated in depressed menopausal women given estrogen. Additionally, most studies evaluating NAS and mood in reproductive-aged women were not controlled or did not differentiate the effects of estrogen from those of progesterone, the immediate steroid precursor of the NAS (Bernardi et al. 2003; Pluchino et al. 2005).

As part of a previously published study on estrogen acceleration of SSRIs in postmenopausal depression (Rasgon et al. 2007), we elected to determine if postmenopausal women with and without major depression exhibit different peripheral levels of the NAS ALLO, THDOC, DHEA, and NAS precursor, PROG. We also investigated whether the administration of a selective serotonin re-uptake inhibitor (SSRI), sertraline with or without the addition of estrogen influenced NAS concentration in postmenopausal women with major depression. Finally, as prior reports of the effect of hormone replacement with estrogen on NAS were uncontrolled and often included progestins, we assessed in a placebo controlled fashion, whether the administration of estradiol to non-depressed menopausal women affected NAS concentrations. We hypothesized that NAS would be lower in the depressed women and that both the administration of the E2 patch and the SSRI would increase NAS concentrations.

\section{Methods}

Postmenopausal women with unipolar depression and controls were recruited from the UCLA Mood Disorders Program, newspaper advertisements, flyers, and other community venues as previously described (Rasgon et al. 2007). Inclusion criteria required cessation of menses for a minimum of 12 months, plasma levels of follicle stimulating hormone (FSH) greater than $40 \mathrm{mIU} / \mathrm{ml}$ and estradiol (E2) levels less than $20 \mathrm{pg} / \mathrm{ml}$. Subjects were required to have a normal mammogram, pelvic examination, and physical examination within 6 months of enrollment in the study. Exclusion criteria included previous estrogen replacement, prior antidepressant exposure, psychiatric 
disorders other than depressive disorder, current use of hormonal medications, current use of tobacco, significant vasomotor symptoms and medical illness in which estrogen use may be contraindicated (cardiac disease, clotting disorders, breast cancer, abnormal uterine bleeding, renal disease, or liver disease). All subjects signed the informed consent form approved by the UCLA Office for Protection of Research Subjects prior to study enrollment. All experimental procedures were conducted in accordance with the Declaration of Helsinki. A Structured Clinical Interview for DSM IV was administered to determine whether subjects met inclusion criteria for major depressive disorder (MDD), and to rule out other Axis I diagnoses.

Both depressed and control subjects were randomized to estrogen or placebo transdermal patches from the onset of the study in a double blind manner. Patches were applied twice weekly to ensure maintenance of adequate estradiol levels, with the estrogen patch release rate of $.1 \mathrm{mg}$ estradiol/day. All depressed subjects received sertraline concurrently with the estrogen or the placebo. The initial dose of sertraline was $50 \mathrm{mg}$ per day for the first week, increased to $100 \mathrm{mg} /$ day for the remainder of the study. The Hamilton Rating Scale for Depression (Ham-D) was conducted at the initial visit and weekly thereafter for ten weeks. Individual items from the HAM-D for psychological anxiety, somatic anxiety, and agitation were used to create an anxiety scale. Baseline phlebotomy was conducted prior to interventions and at the end of ten weeks of treatment to measure serum ALLO, THDOC, DHEA, and PROG as part of the larger study addressing differential treatment response and cognition.

\section{Steroid assay}

Blood samples were collected in tubes containing clotactivating factor and were immediately centrifuged. The serum samples were stored at $-80^{\circ} \mathrm{C}$ until assayed. For the neurosteroid assay, $1 \mathrm{ml}$ of serum was diluted with $2 \mathrm{ml}$ of water and then extracted three times with $3 \mathrm{ml}$ of ethyl acetate. The recovery $(90 \%)$ of steroids through the extraction procedure was monitored by adding a trace amount of $\left[{ }^{3} \mathrm{H}\right]$ cortisol $(6,000-8,000 \mathrm{cpm}, 52 \mathrm{Ci} / \mathrm{mmol})$. The neurosteroids were quantified by radioimmunoassay as previously described (Follesa et al. 2002) with specific antibodies to DHEA and PROG (ICN, Milan, Italy,). Antibodies to ALLO and THDOC were generated in rabbits and sheep, respectively, and were provided by Dr. R.H. Purdy (Scripps Research Institute, La Jolla, Calif., USA). The limit of detection of radioimmunoassay, expressed as minimal amount of steroids distinguishable from the zero sample was $0.01 \mathrm{ng}$. Intra- and inter-assay coefficient of variations ranged between 5 and $7 \%$ and between 9 and $11 \%$, respectively. Estradiol was assayed by commercial kit (ICN Pharmaceuticals, Costa Mesa, Calif., USA).

Data analysis

Independent t-tests were used to assess group differences in demographic and baseline clinical variables. Between and within group changes in NAS levels from baseline to end of treatment were assessed with repeated measures analyses of variance. Multivariate analysis of variance (MANOVA) was used to analyze differences in NAS profiles between depressed subjects and controls. MANOVA was also used to assess group differences in NASs in depressed subjects on sertraline plus estrogen versus sertraline plus placebo. The relationship between mood and NAS concentrations was evaluated with bivariate correlation analyses.

\section{Results}

Demographics Twenty eight postmenopausal subjects were enrolled in the study. Sixteen met criteria for major depressive disorder and 12 were asymptomatic controls. Participants were randomized to receive either estrogen or placebo with 8 depressed and 6 controls receiving estrogen, and 8 depressed and 6 control subjects receiving placebo. Means and standard deviations of age, years since menopause, age at the time of menopause, parity, education, body mass index (BMI), and baseline Ham-D are contained in Table 1. No significant differences were seen between depressed subjects and control subjects in the demographic characteristics with the exception of education. Depressed subjects had significantly less education than controls $(t=3.06, p<.05)$. BMI was higher in the depressed subjects compared with controls however the difference did not reach significance $(p=.052)$. By definition, depressed subjects had significantly higher Ham-D scores than control subjects at baseline.

Baseline differences in NAS between depressed and normal control subjects Table 2 contains descriptive statistics of baseline concentrations of ALLO, THDOC, DHEA, and PROG for depressed and control subject. Prior to treatment, MANOVA revealed a significant omnibus test $\left(\mathrm{F}(4,23)^{)}=\right.$ 4.99, $p=.005)$. Univariate follow-up tests indicated that ALLO and DHEA were significantly lower in the depressed subjects compared to the healthy postmenopausal women $(\mathrm{t}(26)=2.42, p=.023$ and $\mathrm{t}(26)=2.48, p=.020$ respectively $)$.

Change in NASs from baseline to end of treatment Table 3 contains descriptive statistics for NAS before and after estrogen or placebo treatment in depressed menopausal women on SSRIs and healthy menopausal controls. There 
Table 1 Demographic variables

\begin{tabular}{|c|c|c|c|c|c|c|}
\hline & \multicolumn{2}{|c|}{ Depressed $(n=16)$} & \multicolumn{2}{|c|}{ Control $(n=12)$} & \multicolumn{2}{|c|}{ Total $(n=28)$} \\
\hline & Mean & $\mathrm{SD}$ & Mean & $\mathrm{SD}$ & Mean & SD \\
\hline Age & 54.50 & 4.99 & 57.91 & 5.59 & 55.89 & 5.42 \\
\hline Education (years) $^{\mathrm{a}}$ & 14.91 & 1.54 & 17.18 & 2.32 & 15.83 & 2.18 \\
\hline Menopause (years) & 5.33 & 4.40 & 9.06 & 6.68 & 6.73 & 5.54 \\
\hline Age at menopause & 47.33 & 5.75 & 49.39 & 2.89 & 48.10 & 4.91 \\
\hline Parity & 1.40 & 1.35 & 1.55 & 1.21 & 1.46 & 1.27 \\
\hline BMI & 29.38 & 6.23 & 25.45 & 2.78 & 27.70 & 5.35 \\
\hline Baseline Ham- $\mathrm{D}^{\mathrm{b}}$ & 21.75 & 3.49 & 4.08 & 1.73 & 13.75 & 8.93 \\
\hline
\end{tabular}

were no significant differences between or within groups in any of the NASs, nor were there significant interactions.

Effect of SSRI plus estrogen or placebo on NAS In depressed subjects, NAS and PROG did not change significantly after SSRI treatment plus estrogen or SSRI treatment plus placebo.

As reported previously, all of the depressed women responded to treatment with the sertraline (Rasgon et al. 2007). Estrogen did not alter the final response rate to sertraline; however, the estrogen group improved more rapidly than the placebo group (data not shown).

\section{Discussion}

To further understand the role of neuroactive steroids in postmenopausal depression and mechanism of action of estrogen and SSRIs in this disorder, we compared the concentrations of serum ALLO, THDOC, DHEA and the neuroactive precursor PROG between postmenopausal women with depression and asymptomatic postmenopausal controls. Neuroactive steroids were studied before and after the administration of sertraline with the addition of estrogen or placebo in the depressed group, and estrogen or placebo (no SSRI) in the group of asymptomatic postmenopausal women, as part of a larger double blind, placebo controlled study of estrogen augmentation of SSRIs in post menopausal women with depression (Rasgon et al. 2007). The major finding of this current study was significantly lower baseline DHEA and ALLO in postmenopausal women with major depressive disorder compared with healthy controls. In the depressed women, exposure to sertraline failed to affect NAS concentrations. Estrogen administration did not significantly alter NAS levels in either the depressed or control subjects.

Our study supports previously published reports of lower baseline levels of DHEA or DHEA in its sulfated form (DHEAS) in depressed populations compared to controls (Barbaccia et al 2000; Yaffe et al. 1998; Barrett-Connor et al. 1999; Michael et al. 2000; Berr et al. 1996). However, the literature on DHEA and depression is inconsistent with publications also reporting higher levels (Tollefson et al. 1990; Osran et al. 1993; Heuser et al. 1998; Takebayashi et al. 1998), or no differences (Fabian et al. 2001; Erdincler et al. 2004; Romeo et al. 1998). The discrepancy in DHEA results may be explained in part by differences in the age, gender or health of the subjects (Van Broekhoven and Verkes 2003). DHEA clearly declines with age and debility (Orentreich et al. 1984) but our depressed subjects and controls were comparable in age and were all healthy except for the diagnosis of depression. Yaffe et al. (1998) and Barrett-Connor et al. (1999) sampled large numbers ( $n=699$ and 394 respectively) of community dwelling postmenopausal women, and both studies also found DHEAs or DHEA to be non detectable or lower in postmenopausal women with depressive symptoms compared to postmenopausal controls. Barbaccia et al. (2000) had similar findings in a sample of 25 postmenopausal

Table 2 Baseline neuroactive steroid concentrations $(\mathrm{ng} / \mathrm{ml})$ in depressed menopausal women and healthy menopausal controls

\begin{tabular}{lccc}
\hline & Depressed $($ mean $\pm \mathrm{sd}) \mathrm{n}=16$ & Controls (mean $\pm \mathrm{sd}) \mathrm{n}=12$ & $\mathrm{p}$-statistic \\
\hline PROG & $1.07 \pm 0.27$ & $0.96 \pm 0.20$ & -1.19 \\
ALLO & $4.34 \pm 1.14$ & $6.00 \pm 2.34$ & -2.42 \\
THDOC & $1.69 \pm 0.87$ & $4.73 \pm 6.86$ & .243 \\
DHEA & $0.81 \pm 0.49$ & $1.57 \pm 1.09$ & $.023^{\mathrm{a}}$ \\
\hline
\end{tabular}

${ }^{\text {a }}$ Statistically significant difference $(p<.05)$ between depressed subjects and controls in ALLO and DHEA at baseline 
Table 3 Neuroactive steroid concentrations $(\mathrm{ng} / \mathrm{ml})$ before and after estrogen or placebo treatment in depressed menopausal women on SSRIs and healthy menopausal controls

No significant changes in NAS after estrogen or placebo treatment in depressed or healthy menopausal women

\begin{tabular}{|c|c|c|c|c|c|}
\hline & & \multicolumn{2}{|l|}{ Depressed } & \multicolumn{2}{|l|}{ Control } \\
\hline & & Baseline & End of treatment & Baseline & End of treatment \\
\hline \multirow[t]{2}{*}{ PROG } & Placebo & $1.07 \pm 0.37$ & $1.06 \pm 0.13$ & $1.03 \pm 0.16$ & $1.07 \pm 0.26$ \\
\hline & Estrogen & $1.07 \pm 0.14$ & $1.01 \pm 0.23$ & $0.89 \pm 0.23$ & $0.98 \pm 0.26$ \\
\hline \multirow[t]{2}{*}{ ALLO } & Placebo & $4.18 \pm 1.17$ & $3.99 \pm 0.44$ & $7.39 \pm 2.84$ & $6.10 \pm 1.66$ \\
\hline & Estrogen & $4.51 \pm 1.16$ & $4.30 \pm 0.96$ & $4.62 \pm 0.54$ & $8.38 \pm 6.98$ \\
\hline \multirow[t]{2}{*}{ THDOC } & Placebo & $1.64 \pm 1.00$ & $1.84 \pm 0.90$ & $8.19 \pm 8.58$ & $8.98 \pm 10.11$ \\
\hline & Estrogen & $1.75 \pm 0.79$ & $2.00 \pm 0.96$ & $1.28 \pm 1.12$ & $1.23 \pm 1.01$ \\
\hline \multirow[t]{2}{*}{ DHEA } & Placebo & $1.03 \pm 0.49$ & $0.87 \pm 0.58$ & $1.32 \pm 0.90$ & $1.19 \pm 0.48$ \\
\hline & Estrogen & $0.59 \pm 0.41$ & $0.88 \pm 0.80$ & $1.81 \pm 1.29$ & $1.93 \pm 1.04$ \\
\hline
\end{tabular}

depressed women. Morrison et al. (2001) found that lower levels of DHEAs were correlated with higher depressive scores in the older half of the sample (older than 41 years versus younger than 41 years); by contrast, in the younger half of the sample, higher DHEA levels correlated with higher depressive scores. The hypothalamic-pituitaryadrenal (HPA) axis stress response may differ in older compared to younger depressed patients.

Lower plasma DHEA/S has also been associated with higher levels of stress and with trait anxiety (Diamond et al. 1989). We did not find a correlation of NAS with anxiety in our subjects. The role of DHEA in regulating mood remains unknown. DHEAs are negative allosteric modulators of the $\mathrm{GABA}_{\mathrm{A}}$ receptor (Majewska 1992) with paradoxical effects in depression and anxiety as DHEA supplementation has been reported to improve well being and depression in elderly subjects and to be anxiolytic (Wolkowitz et al. 1999; Van Broekhoven and Verkes 2003; Morales et al. 1994; Yen et al. 1995; Wolkowitz et al. 1995).

The DHEA antidepressant action has been attributed, among other theories, to augmentation of serotonin and norepinepherine or to metabolism of DHEA to testosterone or estrogen (Van Broekhoven and Verkes 2003; Morley et al. 1997). As we previously reported, estrogen did accelerate the antidepressant response compared with SSRI treatment alone. We did not however see a change in DHEA concentrations post treatment, which adds to the inconsistent findings of effect of pharmacologic therapy on DHEA levels (Van Broekhoven and Verkes 2003).

Our results also support previous reports of lower ALLO in depressed subjects compared to controls (Romeo et al. 1998; Strohle et al. 1999; Uzunova et al. 1998). However, not all studies have confirmed this relationship. ALLO was found to be higher in depressed subjects than controls by others (Barbaccia et al. 2000; Hardoy et al. 2006). ALLO also produced antidepressive effects in the mouse forced swim test model of depression (Khisti and Chopde 2000) and has been postulated to act via the HPA axis and on serotonin and norepinepherine neurotransmission (Van
Broekhoven and Verkes 2003). However these putative antidepressant effects after the administration of ALLO may not necessarily contribute to the efficacy of pharmacologic therapy. Contrary to the findings of others (Romeo et al. 1998; Uzunova et al. 1998; Strohle et al. 2000), we failed to find an increase in ALLO or THDOC after treatment of depression with SSRIs, suggesting increases in plasma ALLO are not required for treatment response. Other studies utilizing partial sleep deprivation or repetitive transcranial magnetic stimulation to treat depressed subjects also found NAS were not affected by either intervention regardless of response status (Schule et al. 2003; Padberg et al. 2005). This study adds to the body of the literature suggesting that a change in NAS is not essential for successful treatment of depression (with or without pharmacological interventions), or it is possible that the NAS response may occur at later, not initial, stage of antidepressant treatment.

Similarly, we did not find an increase in NAS after estrogen supplementation. Others have found increased ALLO and DHEA in non-depressed postmenopausal women given various regimens of hormone therapy (estrogen, estrogen/progestin, or tibolone), but the studies were not controlled for placebo effect (Bernardi et al. 2003; Pluchino et al. 2005). Additionally, our subjects lacked menopausal symptoms and the increase in NAS found by others could relate to improvement in menopausal symptoms. We also studied a small group of subjects and further studies with larger numbers will be important.

There is considerably less literature on THDOC and depression in clinical populations. Baseline THDOC levels were found to be higher in depressed subjects compared to controls (Strohle et al. 1999; Strohle et al. 2000). Similar to others (Rupprecht and Holsboer 1999; Hardoy et al. 2006), we detected no differences in THDOC in depressed subjects compared to controls. However, the high standard deviation may also account for failure of significance.

A consensus is forming from preclinical and clinical research indicating that neuroactive steroids are involved 
in the pathophysiology of depression and possibly response to treatment. However, a direct correlation with NAS and diagnosis or outcome has not been definitively established in humans. The specificity of the NAS assays can also lead to discrepancies; gas chromatography, mass spectrometry, or high performance liquid chromatography and radioimmunoassays may give different levels of NASs (Pearson Murphy and Allison 2000). Furthermore, the results of this study are limited by the small sample size and the fact that we were unable to compare the effects of sertraline and estrogen on NAS in the early versus late post menopausal state. Further research including central nervous system NAS investigation is also needed.

\section{Declaration}

The authors have no financial or other potential conflict of interest. There is no conflict of interest that could contribute to prejudicing the impartiality of the report. This work was supported in part by grant R29 (NR) from the National Institute of Mental Health and UCLA GCRC (M01RR000865).

Open Access This article is distributed under the terms of the Creative Commons Attribution Noncommercial License which permits any noncommercial use, distribution, and reproduction in any medium, provided the original author(s) and source are credited.

\section{References}

Barbaccia ML, Lello S, Sidiropoulou T, Cocco T, Sorge RP, Cocchiarale A, Piermarini V, Sabato AF, Trabucchi M, Romanini C (2000) Plasma 5alpha-androstane-3alpha, 17betadiol, an endogenous steroid that positively modulates GABA (A) receptor function, and anxiety: a study in menopausal women. Psychoneuroendocrinology 25:659-675

Barrett-Connor E, von Muhlen D, Laughlin GA, Kripke A (1999) Endogenous levels of dehydroepiandrosterone sulfate, but not other sex hormones, are associated with depressed mood in older women: the Rancho Bernardo Study. J. Am. Geriatr. Soc. 47:685-691

Baulieu EE (1991) Neurosteroids: a new function in the brain. Biology of the cell/ under the auspices of the European Cell Biology Organization 71:3-10

Bernardi F, Pieri M, Stomati M, Luisi S, Palumbo M, Pluchino N, Ceccarelli C, Genazzani AR (2003) Effect of different hormonal replacement therapies on circulating allopregnanolone and dehydroepiandrosterone levels in postmenopausal women. Gynecol. Endocrinol. 17:65-77

Bernardi F, Pluchino N, Begliuomini S, Lenzi E, Palumbo M, Luisi M, Genazzani AR (2004) Disadaptive disorders in women: Allopregnanolone, a sensitive steroid. Gynecol. Endocrinol. 19:344-353
Berr C, Lafont S, Debuire B, Dartigues JF, Baulieu EE (1996) Relationships of dehydroepiandrosterone sulfate in the elderly with functional, psychological, and mental status, and short-term mortality: a French community-based study. Proc. Natl Acad. Sci. USA 93:13410-13415

Bethea CL, Lu NZ, Gundlah C, Streicher JM (2002) Diverse actions of ovarian steroids in the serotonin neural system. Front. Neuroendocrinol. 23:41-100

Birkhauser M (2002) Depression, menopause and estrogens: is there a correlation? Maturitas 41:S3-8

Cohen LS, Soares CN, Poitras JR, Prouty J, Alexander AB, Shifren JL (2003) Short-term use of estradiol for depression in perimenopausal and postmenopausal women: a preliminary report. Am. J. Psychiatry 160:1519-1522

Cohen LS, Soares CN, Joffe H (2005) Diagnosis and management of mood disorders during the menopausal transition. Am. J. Med. 118(Suppl 12B):97-93

Concas A, Follesa P, Barbaccia ML, Purdy RH, Biggio G (1999) Physiological modulation of GABA (A) receptor plasticity by progesterone metabolites. Eur. J. Pharmacol. 375:225-235

Diamond P, Brisson GR, Candas B, Péronnet F (1989) Trait anxiety, submaximal physical exercise and blood androgens. Eur J Appl Physiol Occup Physiol 58:699-704

Erdincler D, Bugay G, Ertan T, Eker E (2004) Depression and sex hormones in elderly women. Archives of Gerontology and Geriatrics 39:239-244

Fabian TJ, Dew MA, Pollock BG, Reynolds CF 3rd, Mulsant BH, Butters MA, Zmud MD, Linares AM, Trottini M, Kroboth PD (2001) Endogenous concentrations of DHEA and DHEA-S decrease with remission of depression in older adults. Biol. Psychiatry 50:767-774

Follesa P, Porcu P, Sogliano C, Cinus M, Biggio F, Mancuso L, Mostallino MC, Paoletti AM, Purdy RH, Biggio G, Concas A (2002) Changes in GABA (A) receptor gamma 2 subunit gene expression induced by long-term administration of oral contraceptives in rats. Neuropharmacology 42:325-336

Genazzani AR, Petraglia F, Bernardi F, Casarosa E, Salvestroni C, Tonetti A, Nappi RE, Luisi S, Palumbo M, Purdy RH, Luisi M (1998) Circulating levels of allopregnanolone in humans: gender, age, and endocrine influences. J. Clin. Endocrinol. Metab. 83:2099-2103

Genazzani AR, Bernardi F, Pluchino N, Begliuomini S, Lenzi E, Casarosa E, Luisi M (2005) Endocrinology of menopausal transition and its brain implications. CNS Spectrums 10:449-457

Hardoy MC, Serra M, Carta MG, Contu P, Pisu MG, Biggio G (2006) Increased neuroactive steroid concentrations in women with bipolar disorder or major depressive disorder. J. Clin. Psychopharmacol. 26:379-384

Heuser I, Deuschle M, Luppa P, Schweiger U, Standhardt H, Weber B (1998) Increased diurnal plasma concentrations of dehydroepiandrosterone in depressed patients. J. Clin. Endocrinol. Metab. 83:3130-3133

Joffe H, Cohen LS (1998) Estrogen, serotonin, and mood disturbance: where is the therapeutic bridge? Biol. Psychiatry 44:798-811

Khisti RT, Chopde CT (2000) Serotonergic agents modulate antidepressant-like effect of the neurosteroid 3alpha-hydroxy5alpha-pregnan-20-one in mice. Brain Res. 865:291-300

Khisti RT, Chopde CT, Jain SP (2000) Antidepressant-like effect of the neurosteroid 3alpha-hydroxy-5alpha-pregnan-20-one in mice forced swim test. Pharmacol. Biochem. Behav. 67:137-143

Lambert JJ, Belelli D, Hill-Venning C, Peters JA (1995) Neurosteroids and $\mathrm{GABA}_{\mathrm{A}}$ receptor function. Trends Pharmacol. Sci. 16:295303

Liu P, He FF, Bai WP, Yu Q, Shi W, Wu YY, He DJ, Xiao JH, Zheng Y, Liao QP (2004) Menopausal depression: comparison of 
hormone replacement therapy and hormone replacement therapy plus fluoxetine. Chin. Med. J. 117:189-194

Majewska MD (1992) Neurosteroids: endogenous bimodal modulators of the GABAA receptor. Mechanism of action and physiological significance. Progress in Neurobiology 38:379-395

Matsumoto K, Uzunova V, Pinna G, Taki K, Uzunov DP, Watanabe H, Mienville JM, Guidotti A, Costa E (1999) Permissive role of brain allopregnanolone content in the regulation of pentobarbitalinduced righting reflex loss. Neuropharmacology 38:955-963

Mellon SH, Griffen L (2002) Neurosteroids: Biochemistry and clinical significance. Trends in Endocrine Metabolism 13:35-43

Michael A, Jenaway A, Paykel ES, Herbert J (2000) Altered salivary dehydroepiandrosterone levels in major depression in adults. Biol. Psychiatry 48:989-999

Morales AJ, Nolan JJ, Nelson JC, Yen SS (1994) Effects of replacement dose of dehydroepiandrosterone in men and women of advancing age. J Clin Endocrinol Metab. 78:1360-1367

Morgan ML, Cook IA, Rapkin AJ, Leuchter AF (2005) Estrogen augmentation of antidepressants in perimenopausal depression: a pilot study. J. Clin. Psychiatry 66:774-780

Morley JE, Kaiser F, Raum WJ, Perry HM 3rd, Flood JF, Jensen J, Silver AJ, Roberts E (1997) Potentially predictive and manipulable blood serum correlates of aging in the healthy human male: progressive decreases in bioavailable testosterone, dehydroepiandrosterone sulfate, and the ratio of insulin-like growth factor 1 to growth hormone. Proc. Natl Acad. Sci. USA 94:7537-7542

Morrison MF, Ten Have T, Freeman EW, Sammel MD, Grisso JA (2001) DHEA-S levels and depressive symptoms in a cohort of African American and Caucasian women in the late reproductive years. Biol. Psychiatry 50:705-711

Morrison MF, Kallan MJ, Ten Have T, Katz I, Tweedy K, Battistini M (2004) Lack of efficacy of estradiol for depression in postmenopausal women: a randomized, controlled trial. Biol. Psychiatry 55:406-412

Orentreich N, Brind JL, Rizer RL, Vogelman JH (1984) Age changes and sex differences in serum dehydroepiandrosterone sulfate concentrations throughout adulthood. J Clin Endocrinol Metab 59:551-555

Osran H, Reist C, Chen CC, Lifrak ET, Chicz-DeMet A, Parker L (1993) Adrenal androgens and cortisol in major depression. Am. J. Psychiatry 150:806-809

Padberg F, di Michele F, Zwanzger P, Romeo E, Bernardi G, Schule C, Baghai TC, Ella R, Pasini A, Rupprecht R (2005) Plasma concentrations of neuroactive steroids before and after repetitive transcranial magnetic stimulation (rTMS) in major depression. Neuropsychopharmacology 27:874-878

Paul SM, Purdy RH (1992) Neuroactive Steroids. FASEB J. 6:23112322

Pearson Murphy BE, Allison CM (2000) Determination of progesterone and some of its neuroactive ring A-reduced metabolites in human serum. J. Steroid Biochem. Mol. Biol. 74:137-142

Pinna G, Dong E, Matsumoto K, Costa E, Guidotti A (2003) In socially isolated mice, the reversal of brain allopregnanolone down-regulation mediates the anti-aggressive action of fluoxetine. Proc Natl Acad Sci U S A 100:2035-2040

Pisu MG, Serra M (2004) Neurosteroids and neuroactive drugs in mental disorders. Life Sci. 74:3181-3197

Pluchino N, Genazzani AD, Bernardi F, Casarosa E, Pieri M, Palumbo M, Picciarelli G, Gabbanini M, Luisi M, Genazzani AR (2005) Tibolone, transdermal estradiol or oral estrogen-progestin therapies: effects on circulating allopregnanolone, cortisol and dehydroepiandrosterone levels. Gynecol. Endocrinol. 20:144149

Rasgon NL, Altshuler LL, Fairbanks LA, Dunkin JJ, Davtyan C, Elman S, Rapkin AJ (2002) Estrogen replacement therapy in the treatment of major depressive disorder in perimenopausal women. J. Clin. Psychiatry 63(Suppl 7):45-48

Rasgon NL, Dunkin J, Fairbanks L, Altshuler LL, Troung C, Elman S, Wroolie TE, Brunhuber MV, Rapkin A (2007) Estrogen and response to sertraline in postmenopausal women with major depressive disorder: a pilot study. J. Psychiatr. Res. 41:338-343

Romeo E, Strohle A, Spalletta G, di Michele F, Hermann B, Holsboer F, Pasini A, Rupprecht R (1998) Effects of antidepressant treatment on neuroactive steroids in major depression. Am. J. Psychiatry 155:910-913

Rubinow DR, Schmidt PJ, Roca CA (1998) Estrogen-serotonin interactions: implications for affective regulation. Biol. Psychiatry 44:839-850

Rupprecht R (2003) Neuroactive steroids: mechanisms of action and europsychopharmacological properties. Psychoneuroendocrinology $28: 139-168$

Rupprecht R, Holsboer F (1999) Neuroactive steroids: mechanisms of action and neuropsychopharmacological perspectives. Trends Neurosci. 22:410-416

Schmidt PJ, Nieman L, Danaceau MA, Tobin MB, Roca CA, Murphy JH, Rubinow DR (2000) Estrogen replacement in perimenopause-related depression: a preliminary report. Am J Obst Gynecol. 183:414-420

Schule C, di Michele F, Baghai T, Romeo E, Bernardi G, Zwanzger P, Padberg F, Pasini A, Rupprecht R (2003) Influence of sleep deprivation on neuroactive steroids in major depression. Neuropsychopharmacology 28:577-581

Serra M, Pisu MG, Dazzi L, Purdy RH, Biggio G (2002) Prevention of the stress-induced increase in the concentration of neuroactive steroids in rat brain by long-term administration of mirtazapine but not of fluoxetine. J. Psychopharmacol. 16:133-138

Soares CN, Almeida OP, Joffe H, Cohen LS (2001) Efficacy of estradiol for the treatment of depressive disorders in perimenopausal women: a double-blind, randomized, placebo-controlled trial. Arch. Gen. Psychiatry 58:529-534

Stoffel-Wagner B (2001) Neurosteroid metabolism in the human brain. European Journal of Endocrinology/European Federation of Endocrine Societies 145:669-679

Strohle A, Romeo E, Hermann B, Pasini A, Spalletta G, di Michele F, Holsboer F, Rupprecht R (1999) Concentrations of 3 alphareduced neuroactive steroids and their precursors in plasma of patients with major depression and after clinical recovery. Biol. Psychiatry 45:274-277

Strohle A, Pasini A, Romeo E, Hermann B, Spalletta G, di Michele F, Holsboer F, Rupprecht R (2000) Fluoxetine decreases concentrations of 3 alpha, 5 alpha-tetrahydrodeoxycorticosterone (THDOC) in major depression. J. Psychiatr. Res. 34:183-186

Strous RD, Maayan R, Weizman A (2006) The relevance of neurosteroids to clinical psychiatry: from the laboratory to the bedside. Eur. Neuropsychopharmacol. 16:155-169

Takebayashi M, Kagaya A, Uchitomi Y, Kugaya A, Muraoka M, Yokota N, Horiguchi J, Yamawaki S (1998) Plasma dehydroepiandrosterone sulfate in unipolar major depression. Short communication. J Neural Transm 105:537-542

Tollefson GD, Haus E, Garvey MJ, Evans M, Tuason VG (1990) 24Hour urinary dehydroepiandrosterone sulfate in unipolar depression treated with cognitive and/or pharmacotherapy. Ann. Clin. Psychiatry 2:39-45

Uzunova V, Sheline Y, Davis JM, Rasmusson A, Uzunov DP, Costa E, Guidotti A (1998) Increase in the cerebrospinal fluid content of neurosteroids in patients with unipolar major depression who are receiving fluoxetine or fluvoxamine. Proceedings of the National Academy of Sciences of the USA 95:3239-3244

Uzunova V, Ceci M, Kohler C, Uzunov DP, Wrynn AS (2003) Region-specific dysregulation of allopregnanolone brain content 
in the olfactory bulbectomized rat model of depression. Brain Res. 976:1-8

Uzunova V, Wrynn AS, Kinnunen A, Ceci M, Kohler C, Uzunov DP (2004) Chronic antidepressants reverse cerebrocortical allopregnanolone decline in the olfactory-bulbectomized rat. Eur. J. Pharmacol. 486:31-34

Uzunova V, Sampson L, Uzunov DP (2006) Relevance of endogenous 3alpha-reduced neurosteroids to depression and antidepressant action. Psychopharmacology 186:351-361

Van Broekhoven F, Verkes RJ (2003) Neurosteroids in Depression. A review Psychopharmacology 165:97-110

Westlund Tam L, Parry BL (2003) Does estrogen enhance the antidepressant effects of fluoxetine? J. Affect. Disord. 77:87-92

Wolkowitz OM, Reus VI, Roberts E, Manfredi F, Chan T, Ormiston S, Johnson R, Canick J, Brizendine L, Weingartner $H$ (1995) Antidepressant and cognition-enhancing effects of
DHEA in major depression. Ann NY Acad Sci. 29(774):337339

Wolkowitz OM, Reus VI, Keebler A, Nelson N, Friedland M, Brizendine L, Roberts E (1999) Double-blind treatment of major depression with dehydroepiandrosterone. Am. J. Psychiatry 156:646-649

Yaffe K, Ettinger B, Pressman A, Seeley D, Whooley M, Schaefer C, Cummings S (1998) Neuropsychiatric function and dehydroepiandrosterone sulfate in elderly women: A prospective study. Biol. Psychiatry 43:694-700

Yen SS, Morales AJ, Khorram O (1995) Replacement of DHEA in aging men and women. Potential remedial effects. Ann NY Acad Sci 774:128-142

Zweifel JE, Obrien WH (1997) Meta-analysis of the effect of hormone replacement therapy upon depressed mood. Psychoneuroendocrinology 22:189-212 